\title{
Angiofollicular and plasmacytic polyadenopathy: a pseudotumourous syndrome with dysimmunity
}

\author{
J DiEBOld,* M TUlliez,* A BERNADOU, $\dagger$ J AUdOUIN,* G TRICOT,* \\ M REYNES,* AND G BILSKI-PASQUIER $†$
}

From the *Service Central d'Anatomie et de Cytologie Pathologiques, and †Clinique Hématologique, Hotel-Dieu, 1 place du Parvis Notre Dame, 75181 Paris, Cedex 04, France

SUMMARY Two cases are reported of an apparently distinct type of immune disorder. Beginning with mild anaemia and widespread massive lymphadenopathy, the disease progressed to a fatal autoimmune type haemolytic anaemia. Serum investigation showed polyclonal hypergammaglobulinaemia and some autoantibodies. Repeat lymph node biopsies in each case showed hyperplasia within B lymphocyte territory (follicular hyperplasia and polyclonal plasmacytosis with IgG predominance) and atrophy of $T$ dependent areas. Dilatation of lymph sinuses, vascular proliferation, ànd sclerosis were striking features. This appears to be a new entity, and reasons are given for separating this disease from other pseudotumourous lymph node disorders associated with dysimmunity.

The understanding of diseases in which immune disorders occur in association with pseudotumourous changes in the lymphoid organs has progressed greatly in the past few years. The two patients in this study had pseudotumourous polyadenopathy and disturbed immunity, progressing to a fatal termination. The closely similar clinical symptoms and biological behaviour in these cases suggest a distinct clinicopathological entity of unknown aetiology.

\section{Material and methods}

Both patients were followed in the Haematology Department of the Hotel-Dieu Hospital in Paris. The histological study of case 1 was carried out on biopsy and necropsy specimens using haemateineosin-safranin, PAS, Giemsa, Perl's stain, and Gordon and Sweet's silver impregnation methods. Immunoglobulin production was detected by a direct immunocytochemical fluorescent method on Bouin's fixed, paraffin-embedded material. ${ }^{1}$ The sera used were TITC anti-IgA, -IgG, -IgM, -K, and $-\lambda$ (Miles Laboratories). Immunoelectrophoresis was used to check the specificity of each serum. The preparations were examined using a Leitz Ortholux microscope, with a Ploem system having an Osram

Received for publication 14 May 1979
HBO 200 bulb (excitation filters BG 12 and 38, and screening filter $\mathrm{K} \mathrm{530)}$.

In case 2, slices of lymph nodes were also fixed in buffered formalin, $\mathrm{pH} 7 \cdot 2$, and embedded in epoxy resin. Large, 2 microns thick sections were stained by haematein eosin, PAS, Giemsa, and silver impregnation. Electron microscopical study was performed after $3 \%$ glutaraldehyde fixation. Thin sections were stained with lead citrate and uranyl acetate and then examined with a Siemens Elmiscop 101 microscope.

Results

CASE 1

A 68-year-old Turkish man was admitted to hospital in 1971 with a normocytic, normochromic anaemia, splenomegaly, and multiple enlarged superficial lymph nodes. Lymphography showed enlarged iliac nodes with some pooling of contrast medium. Sternal puncture and bone marrow biopsy disclosed erythroblastic hyperplasia, eosinophilia, and intense plasmacytosis. The Coombs' test was negative.

Several consecutive lymph node biopsies excluded a malignant lymphoproliferative disease, and a liver biopsy showed only a non-specific interstitial hepatitis.

Until October 1971 the condition of the patient remained unchanged. At that time he was readmitted 
to hospital with an increase in the size of the spleen and a worsening of the anaemia with a positive direct Coombs' test (complement type). The most significant findings then were (1) elevation of the serum proteins $(100 \mathrm{~g} / \mathrm{l})$ with polyclonal hypergammaglobulinaemia $(50 \mathrm{~g} / \mathrm{l})$, involving mostly the IgG fraction with both types of light chains; (2) absence of Bence Jones proteinuria; (3) low levels of anti-smooth muscle antibodies, but neither antinuclear nor anti-gastric antibodies; and (4) total cutaneous anergy. Despite treatment with corticosteroids, the patient died three weeks later of an acute haemolytic anaemia ( $\mathrm{Hb} 4.7 \mathrm{~g} / \mathrm{dl}$ ) with diarrhoea, fever, and acute renal failure.

\section{Pathological findings}

Four consecutive lymph node biopsies were performed ( 3 axillary nodes averaging $2.5 \mathrm{~cm}$ in length and a spinal node $1 \mathrm{~cm}$ in diameter). The appearance of all the nodes was the same on microscopy. While the nodal architecture was preserved, there was striking follicular hyperplasia, atrophy of the deep cortex, and intense plasmacytosis (Fig. 1). The plasma cells were mature, sometime bi- or trinucleate, with a few proplasmacytes and plasmablasts. These cells were found in the medullary cords, the subcapsular cortex, and the interfollicular zones as well as in the germinal centres. An immunofluorescent study showed the polyclonal nature of the plasma cells and confirmed the IgG predominance (Table). In addition, it was noted that all the sinuses were distended, and there was a great increase of blood vessels, particularly in the cortex. The hypervascularisation consisted not only in an increase in the number of capillaries (chiefly those in the follicular centres which appeared tortuous with endothelial hyperplasia and luminal narrowing), but also in hyperplasia of postcapillary venules and the

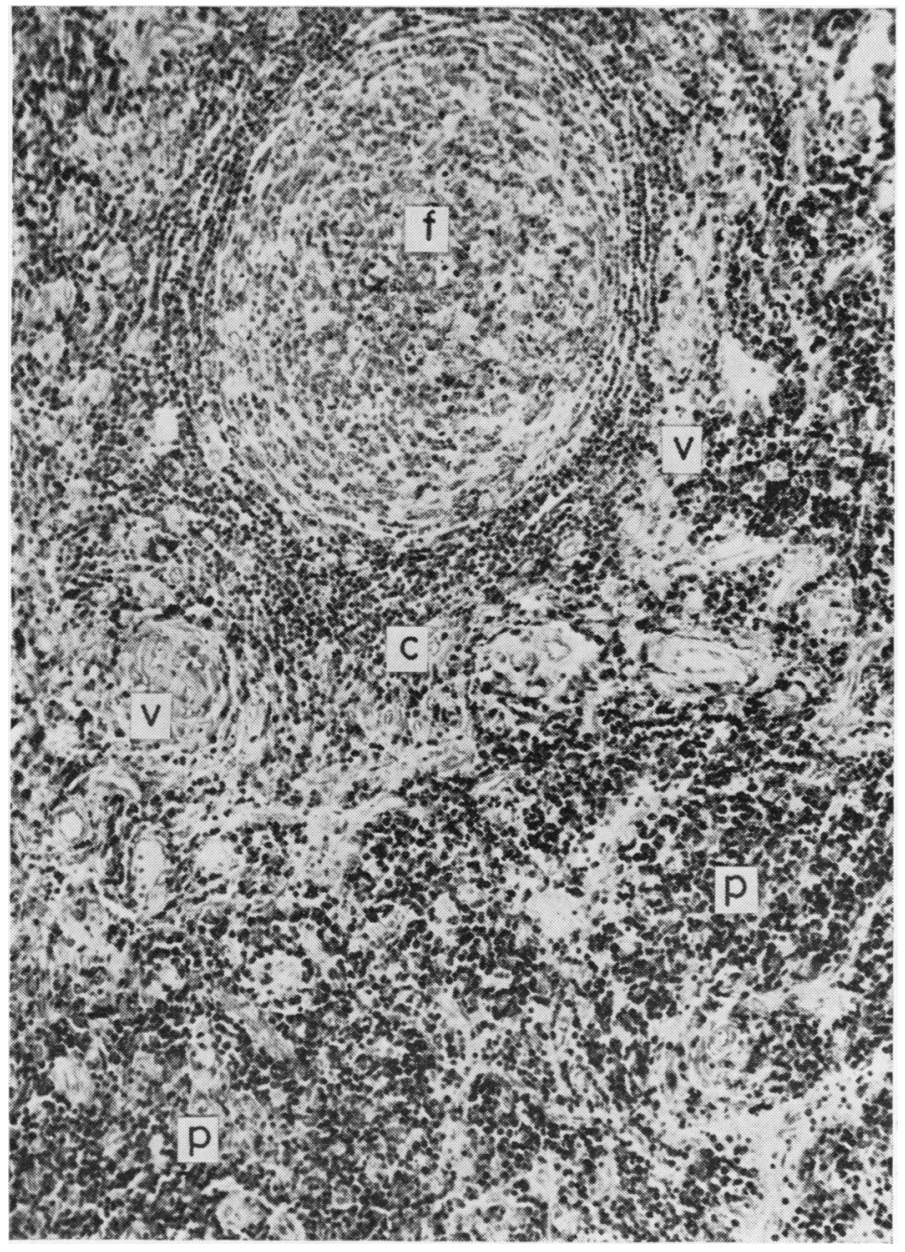

Fig. 1 Case 1. Lymph node (Giemsa's stain $\times 120)$. Follicular hyperplasia $(f)$ with vascular hyperplasia (v), medullary plasmacytosis $(p)$, and atrophy of the paracortical area $(c)$. 


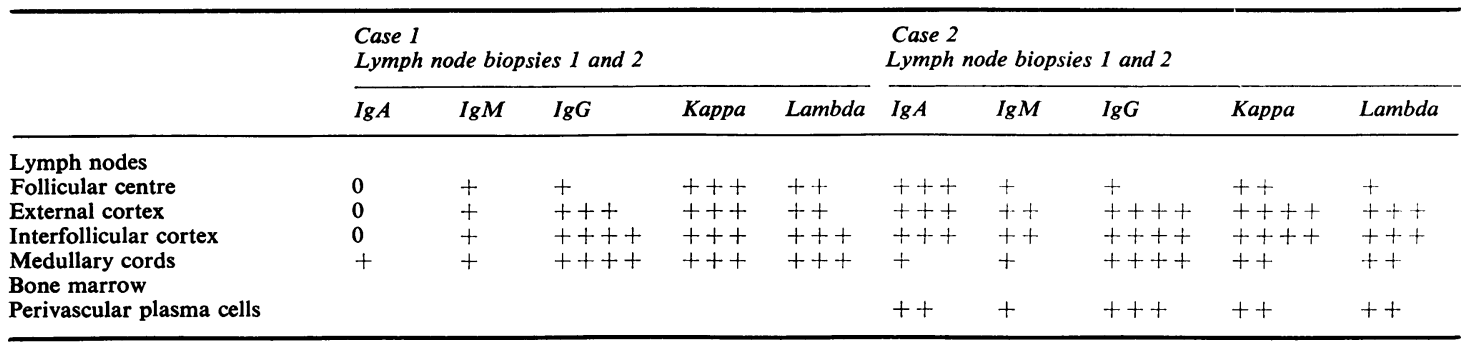

Quantity of plasma cells in one high-power field $(\times 250)$ :

$$
\begin{array}{ll}
+ & 3-10 \text { cells } \\
+t & 11-20 \text { cells } \\
+t+ & 21-30 \text { cells } \\
+t+t & =30 \text { cells }
\end{array}
$$

presence of conspicuous arterial anastomoses traversing the capsule to join with perinodal vessels. There was marked fibrosis around the vessels and sinuses, radiating from the hilum of the node (Fig. 2). There was sometimes concentric fibrosis in the follicle centres associated with an increase of reticulum cells and numerous hyaline deposits. Finally, there were several small capillary 'haemangiomas' in the hilum and capsule.

\section{Necropsy findings}

These included (1) diffuse enlargement of superficial and deep lymph nodes (abdominal, para-aortic, and mediastinal), which showed the previously described histological changes (except for the sinus 'haemangiomas'); (2) a grossly enlarged spleen (1900 g) which showed diffuse hyperplasia of lymphatic tissue, predominantly of the periarterial sheath and the periphery of the germinal centres ( $T$ dependent areas). The small persistent germinal centres were outlined by fibrous tissue, and several small 'splenomas' (splenic hamartomas) were present. As is usual in haemolytic anaemias, numerous macrophages containing red cells or haemosiderin pigment were seen. Plasma cells were abundant in the periarterial areas of the splenic cords; (3) the liver sections showed Kupffer cell hyperplasia with erythrophagocytosis and haemosiderosis; (4) bone marrow preparations showed erythroblastosis and perivascular plasmacytosis with Russell bodies.

Other findings were: chronic interstitial nephritis of the kidneys, widespread terminal bronchopneumonia, and signs of obsolete tuberculosis in the lungs and uraemic pericarditis.

CASE 2

A 66-year-old Polish man was admitted to hospital in December 1977 with multiple enlarged superficial lymph nodes $(2-5 \mathrm{~cm}$ in diameter) which had been

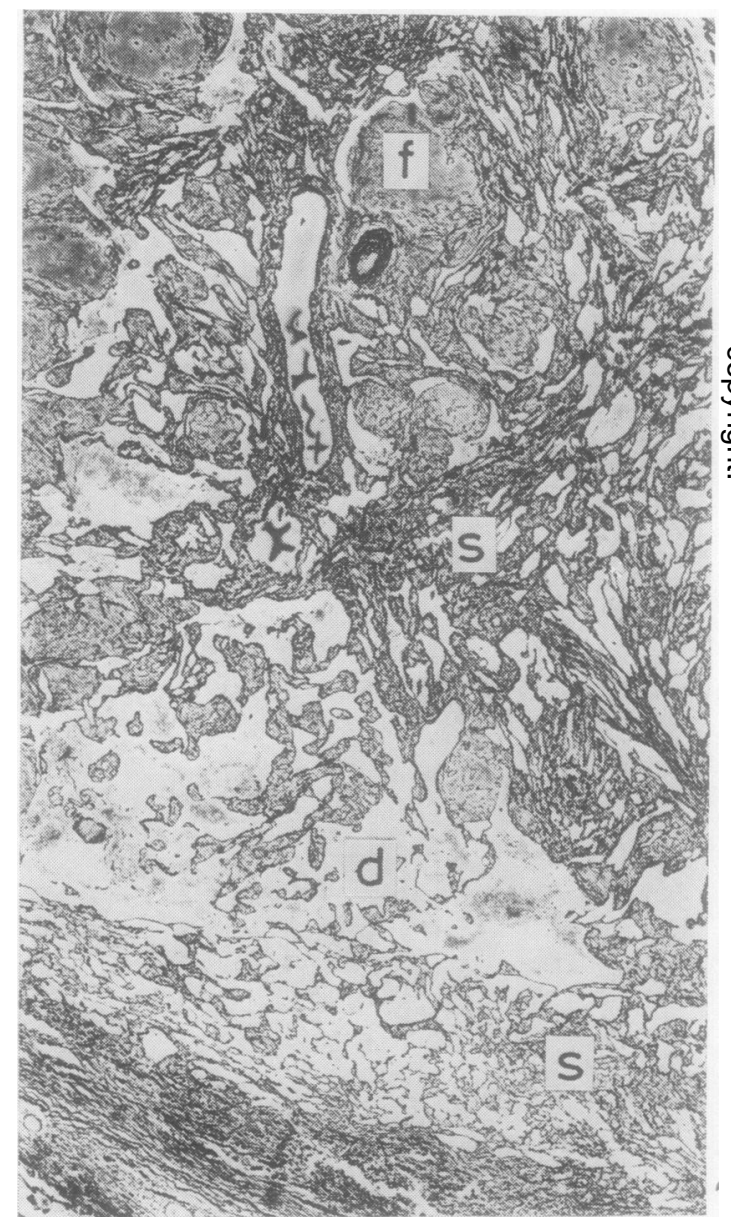

Fig. 2 Case 1. Lymph node (Gordon and Sweet's silver stain $\times 30$ ). Follicular hyperplasia $(f)$ with dilatation of the medullary and interfollicular sinuses $(d)$. Perivascular collagen sclerosis $(s)$. 
noted for 15 years. Blood investigations revealed (1) slight normocytic, normochromic anaemia; (2) a negative Coombs' test; (3) raised serum proteins $(90 \mathrm{~g} / \mathrm{l})$ with gammaglobulins $36 \mathrm{~g} / \mathrm{l}$. Bone marrow aspiration and biopsy showed erythroblastic hyperplasia, eosinophilia, and plasmacytosis of polyclonal type but with IgG predominance (Table). Two consecutive lymph node biopsies showed changes identical with those of case 1 .

In March 1978, there was a further increase in the size of the nodes, and the patient developed a sicca syndrome, which was confirmed by a positive Schirmer's test and grade IV changes in a labial salivary gland biopsy according to the Chisholm classification ( 2 periductal nodular lymphocytic infiltrates without germinal centre formation in a $4 \mathrm{~mm}^{2}$ field).

Serum investigation at this time showed polyclonal hypergammaglobulinaemia with an increase of $\operatorname{IgG}(50 \mathrm{~g} / \mathrm{l})$ and $\operatorname{IgM}(3.6 \mathrm{~g} / \mathrm{l})$, a small amount of cryoglobulin, and the presence of anti-gastric and anti-salivary gland autoantibodies. No other autoantibodies were found.

Lymphography revealed a lymphatic block above the right iliac chain with pooling in the enlarged nodes below (Fig. 3).

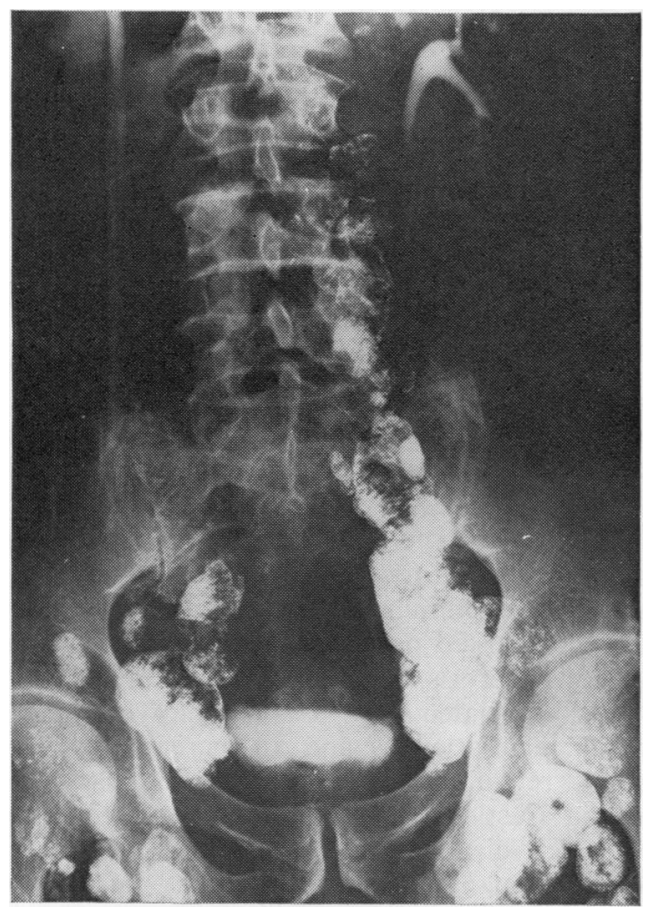

Fig. 3 Case 2. Lymphography. Enlargement of iliac lymph nodes.
The patient was started on corticosteroids combined with antituberculosis therapy. Three months later, he was admitted to another hospital with acute haemolytic anaemia ( $\mathrm{Hb} 4.4 \mathrm{~g} / \mathrm{dl}$ ) and acute coronary insufficiency and died shortly after admission. Necropsy was not performed.

\section{Pathological findings}

The two lymph node biopsies, right cervical $(2 \times 2 \mathrm{~cm})$ and axillary $(7 \times 5 \times 3.5 \mathrm{~cm})$, showed the same changes as were found in case 1, namely, retention of normal architecture with follicular hyperplasia, atrophy of the deep cortex, massive plasmacytosis (polyclonal with IgG predominance) (Fig. 6), capillary hypervascularisation with postcapillary venular hyperplasia, distension of the sinuses, and perivascular and perisinusoidal sclerosis (Figs 4 and 5). The small sinusoidal 'haemangiomas' seen in case 1 were, however, absent.

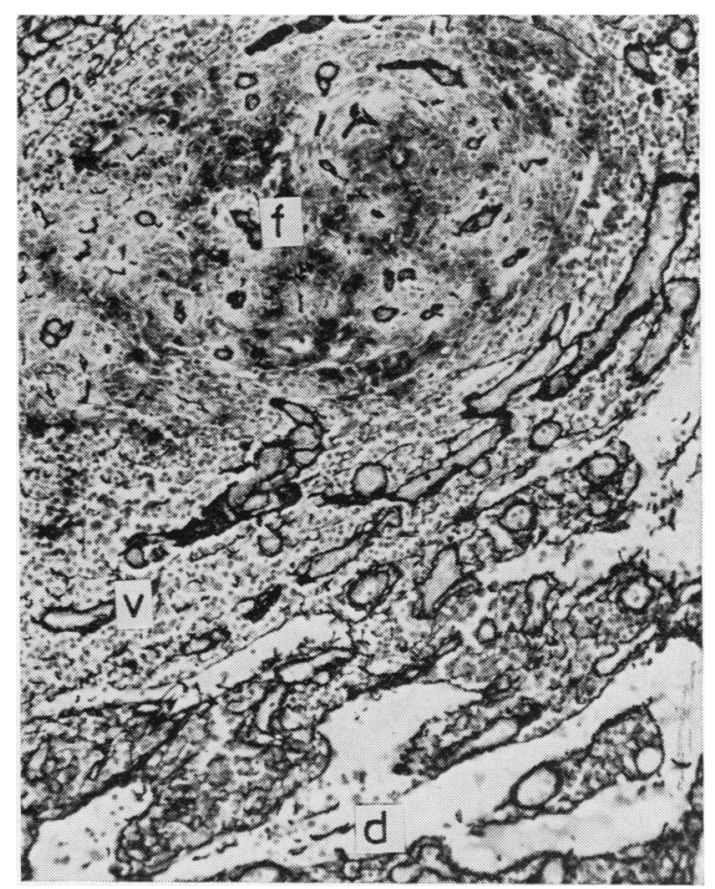

Fig. 4 Case 2. Lymph node (Gordon and Sweet's silver stain $\times 145)$. Follicular hyperplasia $(f)$ with vascular hyperplasia $(v)$ and distension of a sinus $(d)$.

Ultrastructural studies confirmed the striking plasmacytosis. The cells, sometimes bi- or tri-nucleate, showed signs of intense activity in the size of the Golgi apparatus and prominent nucleoli. The sclerosis consisted of an increased number of reticulum cells in contact with an abnormally coarse 


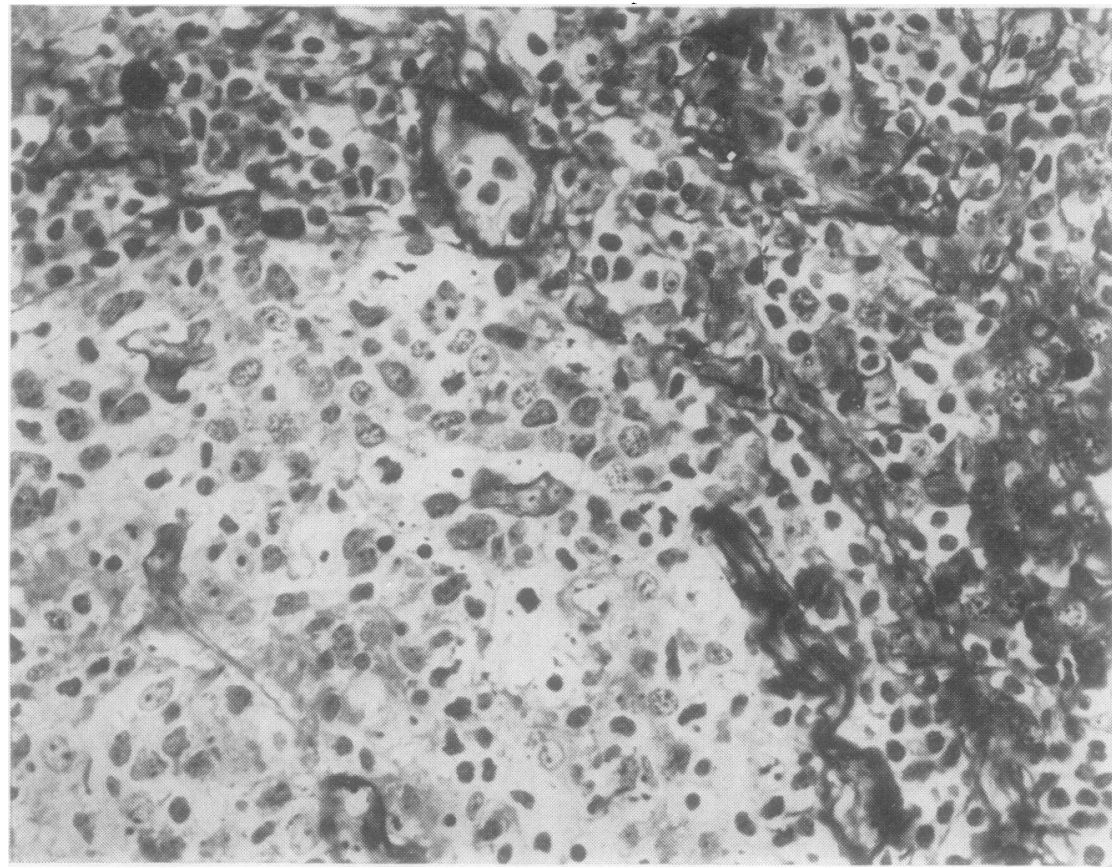

Fig. 5 Case 2. Lymph node (epoxy resin$P A S \times 420)$. Large follicular centre with some plasma cells. Interfollicular clusters of plasma cells. Vascular hyperplasia.

fibre framework. This was made up of layers of granulofilamentous material with variable amounts of collagen and banded structures or 'Luses' bodies' running in all directions. This material surrounded the arterioles, capillaries, and post-capillary venules. The endothelial cells were voluminous with numerous cytoplasmic organelles, filaments, and WeibelPalade bodies. Some capillaries and postcapillary venules had thick and sometimes multilayered basement membranes. In the follicles, reticulum cells were numerous and were arranged in concentric layers. There were few dendritic cells. The other cells observed were lymphocytes, immunoblasts, and some plasma cells (Fig. 7).

\section{Discussion}

The two patients described suffered from a distinctive immune disorder, the anatomical and clinical features of which differ from those found in other recognised tumours or pseudotumours of the lymphoid system associated with disturbed immunity.

In both patients the disease began with progressive enlargement of superficial and deep lymph nodes and hepatosplenomegaly, but without the constitutional symptoms such as might be expected in malignant lymphoma. Investigations revealed anaemia, which was mild at first but which later developed into an acute haemolytic anaemia
(Coombs' test positive in case 1; negative in case 2) Case 2 presented a clinically latent Gougerot Sjögren syndrome, which was confirmed by labia salivary gland biopsy, but, except for this and the haemolytic anaemia, there were no other signs of autoimmunity. There was also a polyclonal hypergammaglobulinaemia with IgG predominance, and cutaneous anergy was present.

Histological studies on the grossly enlarged lymph nodes disclosed preservation of structure (Fig. 2) with pronounced follicular hyperplasia (Figs 1 and 5) striking plasmacytosis, and atrophy of the deep cortical zone(T-dependent). The lymph node plasma cells were polyclonal with IgG predominance (Fig. 6), asshown by immunofluorescence (Table) after paraffin embedding. ${ }^{1}$ Plasmacytosis with the same characteristics was also found in the spleen and bone marrow. In addition, the lymph nodes showed distension of the sinuses, a predominantly cortical hypervascularisation and marked perivascular and perisinusoidal collagenous sclerosis, beginning at the hilum (Fig. 3). This was associated with a sometimes concentric centrofollicular sclerosis and an increase of fibroblasts and reticulum cells around the capillaries, as is seen in Castleman's pseudolymphoma. Hyaline deposits were also seen. In case 1, the small nodular capillary haemangiomas in the hilar region and capsule of the lymph nodes and in the spleen were probably coincidental. 


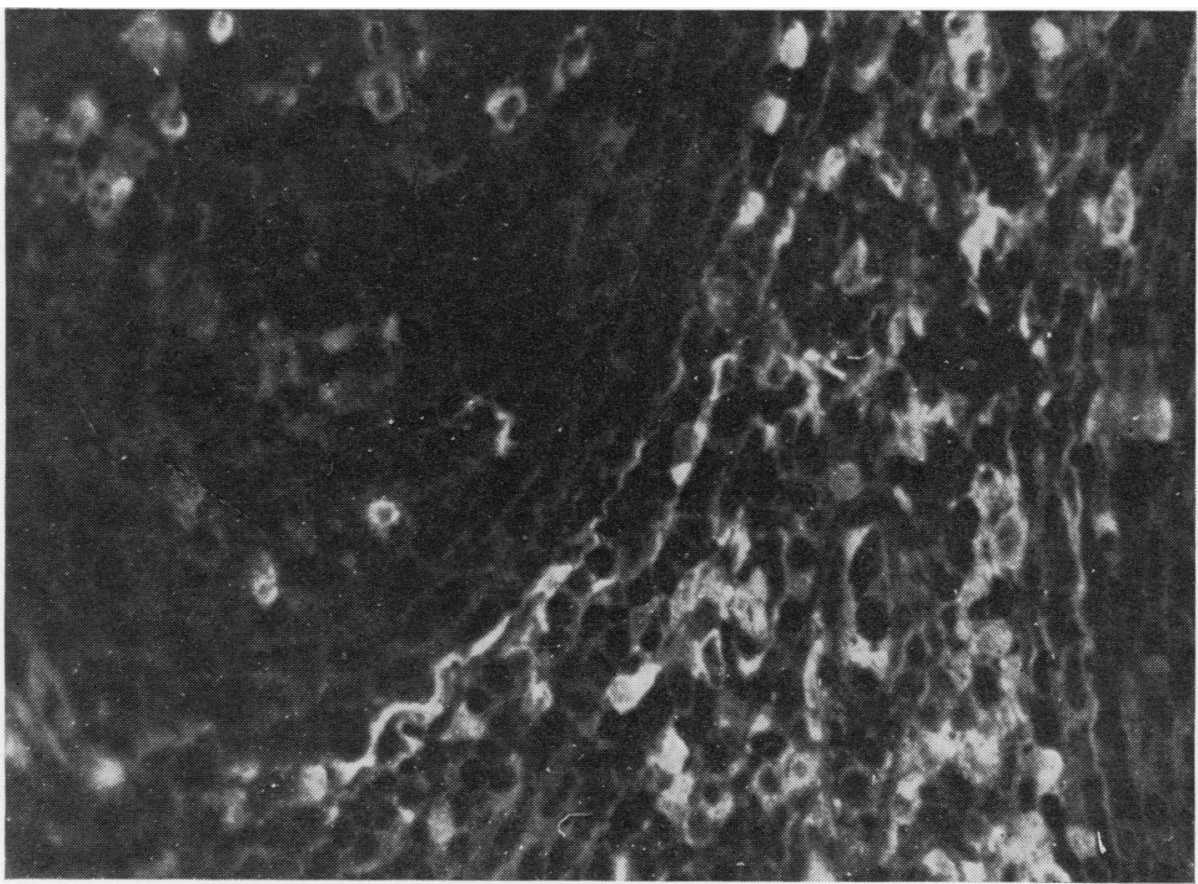

a

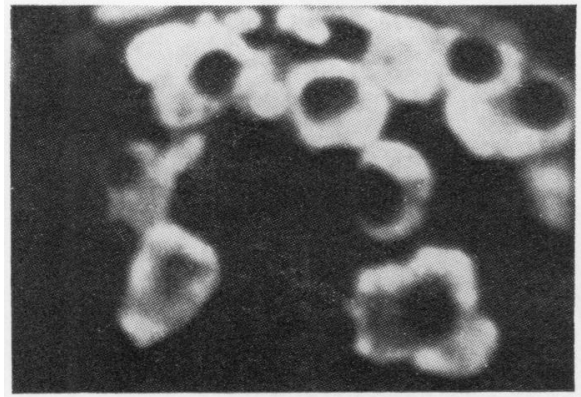

Fig. 6 Case 2. Lymph node (immunofluorescence $\times 400$ ). (a) Numerous plasma cells containing $\operatorname{Ig} G$ in the follicular centre and in the interfollicular area $(\times 1000)$. (b) Detail of IgG containing plasma cells.

It is important to keep in mind that both patients gave a history of treated pulmonary tuberculosis. Finally, concerning the evolution of the disease, it should be noted that, in both cases, death followed an exacerbation of the haemolytic anaemia.

This disorder is distinct from other closely related states. Clinically, the problem is one of tumour-like enlargement of lymph nodes in which lymph node biopsy is essential to distinguish this pseudotumourous hyperplasia from malignant lymphoma. Among the disorders in which pseudotumourous lymphoid hyperplasia is found, it is necessary to discuss only those conditions which are associated with an autoimmune haemolytic anaemia and polyclonal hypergammaglobulinaemia. The latter is rarely found with superficial adenopathy, ${ }^{2}$ although a few such cases are reported. ${ }^{34}$ There are, however, several case reports of pseudotumourous deep lymph node enlargement, discovered by lymphography, in which biopsy excluded a diagnosis of malignant lymphoma. ${ }^{2}$ Histopathological study is thus essential to exclude other diseases. The preservation of the nodal architecture and the polyclonal nature of the plasmacytosis are sufficient to eliminate a malignant lymphoma, in particular nodular lymphoma (formerly Brill-Symmers giant follicular lymphoma). The observed follicular hyperplasia resembles that seen in lymph nodes in some collagenoses, especially 


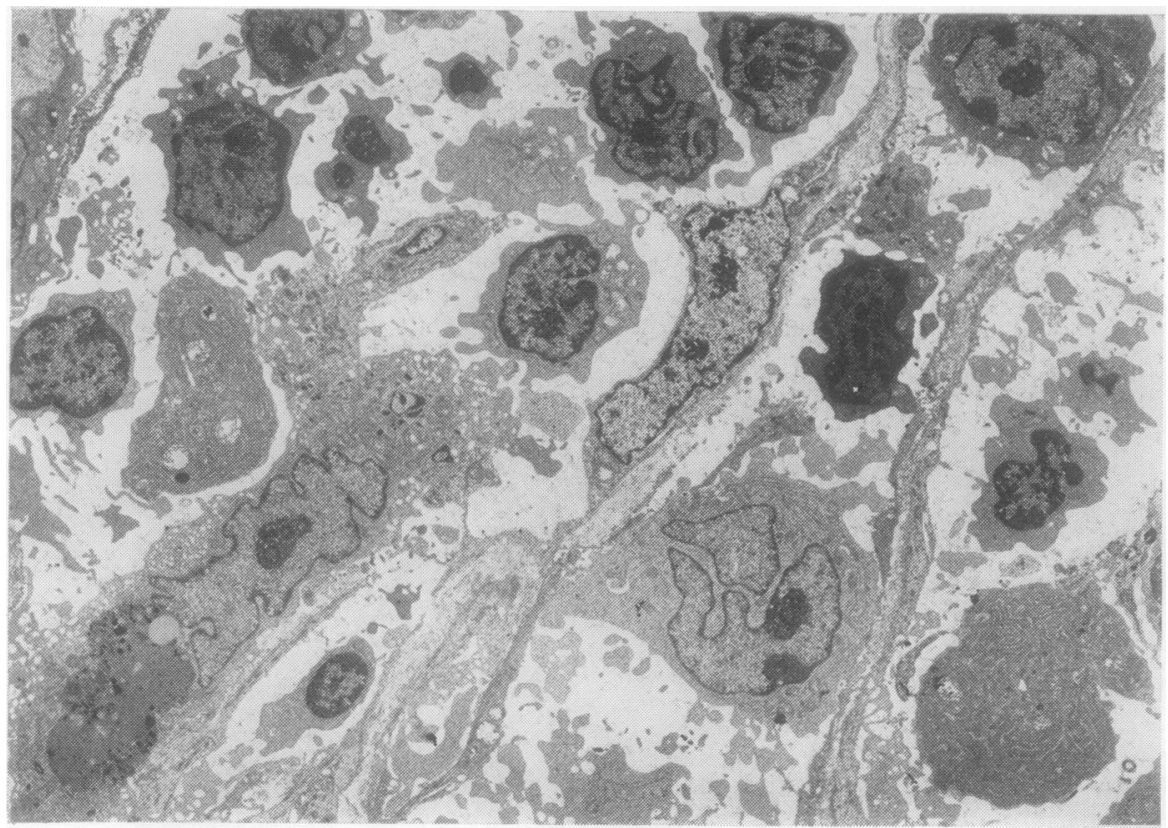

Fig. 7 Case 2.

Lymph node.

(a) Reticulum cell hyperplasia in a follicular centre. $\times 27000$.

(b) Numerous banded structures near a reticulum cell. $\times 32000$.

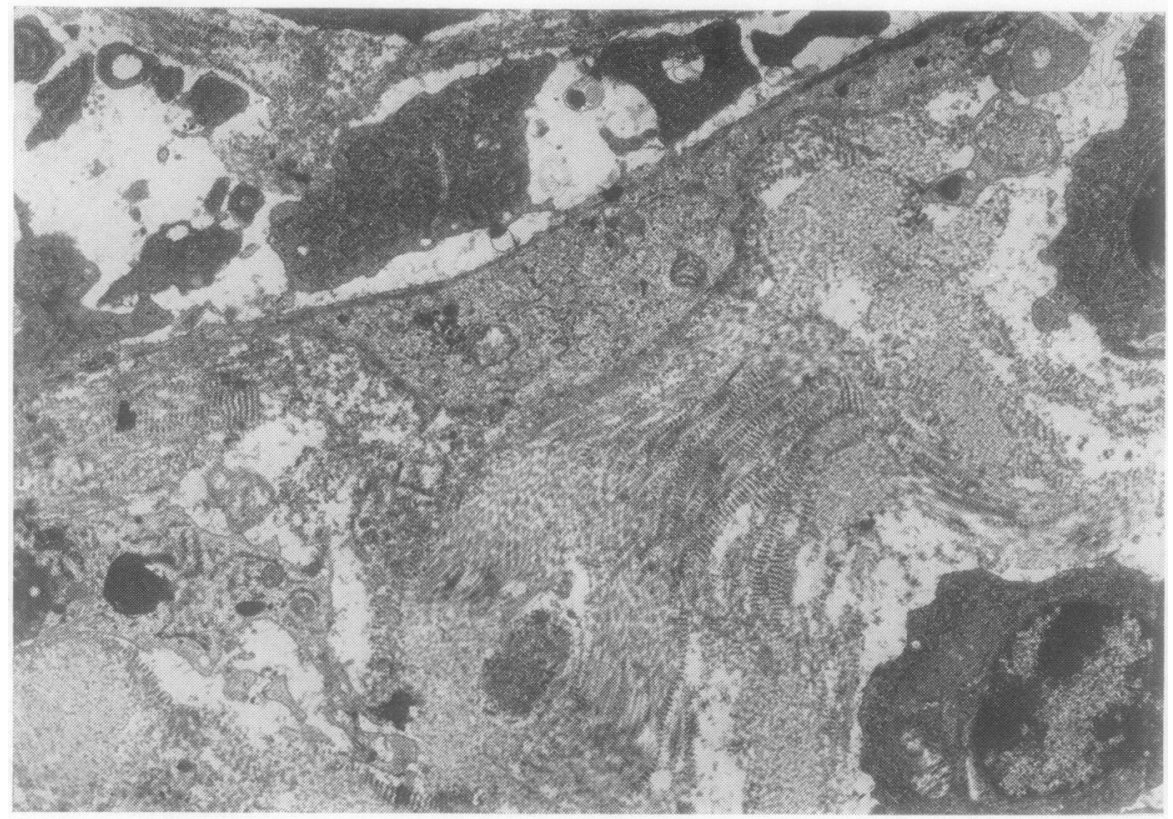

rheumatoid disease and disseminated lupus erythematosus. However, these differ not only in their very different clinical background, but in the relative lack of atrophy of the deep cortex, the lesser degree of plasmacytosis (predominantly IgM), and the absence of sclerosis or sinus distension.

फ्山

$\overrightarrow{\vec{I}}$

요 $\infty$ 은

$$
\vec{z}
$$$$
\text { วั) }
$$$$
\text { 市 }
$$$$
\text { 궁 }
$$

$\overrightarrow{0}$

응 용

$\leq$.

윽웅 
The widespread lymph node involvement allows the exclusion of conditions like the rare vascular transformation of the sinuses 5 and angiofollicular lymphoid hyperplasia (Castleman's pseudolymphoma). ${ }^{6-8}$ In the latter disease, while there are hyperplastic follicles resembling those seen in the nodes in our cases, the normal architecture is lost, and in between the follicles lie numerous plasma cells and capillaries which are not organised in medullary cords. The degree of sclerosis associated with the angiomatoid lesions in case 1 raises the possibility of lymph node localisation of Kaposi's disease, even more so since follicular hyperplasia, intense plasmacytosis, occasionally polyclonal hypergammaglobulinaemia, ${ }^{9}$ and even autoimmune haemolytic anaemia ${ }^{10}$ have been described in this disease. However, the absence of haemosiderin deposits and the total lack of fibroblastic proliferation exclude the diagnosis. ${ }^{911}$ The pseudolymphomatous hyperplasia in the Gougerot-Sjögren syndrome is also different, ${ }^{12-14}$ although this needs to be considered since features of this syndrome were found in case 2 . It generally affects a solitary enlarged node in which the normal architecture is lost as a result of diffuse lymphoid hyperplasia with the presence of numerous immunoblasts and sometimes epithelioid cells.

Finally, the lymph node lesions of our two cases are very different from those seen in angioimmunoblastic lymphadenopathy (AILD), ${ }^{1516}$ also known as lymphogranulomatosis. ${ }^{17} \mathrm{We}$ wish to stress the differences between our description of the histological changes in this disease and those of AILD. In the latter, there is no follicular hyperplasia, only the remains of 'burned out' follicles: furthermore, the architecture is destroyed. The cell population can be rich in plasma cells but consists chiefly of large numbers of immunoblasts.

The vascular hyperplasia is found only in postcapillary venules, which show a PAS positive parietal thickening due to a multilayered basement membrane. There is not the same degree of fibrosis in AILD, but marked perinodal infiltration is a constant finding. Apart from the lymph node changes, our patients lacked the clinical symptoms of AILD - alteration of general health, fever, itching, and cutaneous rashes.

The lymph node changes in our cases are also different from the lesions due to hypersensitivity to drugs, ${ }^{18}$ known viral infections, and post-vaccination reaction, in which the hyperplasia is predominantly immunoblastic.

All things considered, the disease in our two patients has only one point in common with the diseases we have discussed, namely, a pseudotumourous enlargement of lymph nodes in which a polyclonal B lymphocyte hyperplasia is associated with manifestations of disturbed immunity.

The pathogenesis of this disease, as in many dysimmunity diseases, seems to be either an uncontrolled virus or drug-induced B lymphocyte hyperplasia or a B lymphocyte hyperplasia due to a deficit in $\mathrm{T}$ lymphocyte suppressors. These two hypotheses could be combined if, in the autoimmune manifestations, there was a secretion of anti $T$ lymphocyte antibodies which selectively destroyed the precursors of $T$ cell suppressors, as has been seen in the spontaneous diseases of first generation NZB-NZW mice. ${ }^{19} 20$

The discovery of the aetiology of such dysimmunity conditions should be of major concern. In our patients, the search was negative. As to the treatment, it remains unsatisfactory and difficult; only corticosteroid treatment coupled with antituberculosis therapy seems indicated.

We are indebted to Dr AG Stansfeld for his help in improving the English manuscript. We also acknowledge the photographic assistance of $\mathbf{M r}$ Wolfelsperger.

\section{References}

${ }^{1}$ Diebold J, Tricot G, Berault J, Camilleri JP. Mise en évidence des immunoglobulines intracellulaires par immunofluorescence directe sur coupe histologique après fixation par le liquide de Bouin et inclusion en paraplast. Ann Ana Path 1976;20:183-90.

2 James JM. Aspects lymphographiques évoquant un sarcome au cours d'affections auto-immunes et de deficits immunitaires primitifs. Thèse, Paris, 1974.

${ }^{3}$ Dacie JV. The Haemolytic Anaemias: Congenital and Acquired. Part II: The auto-immune anaemias. 2nd ed. London: Churchill, 1962;384.

4 Pirofsky B. Auto-immunisation and the Auto-Immune Hemolytic Anaemia. Baltimore: Williams and Wilkins, $1969 ; 118-46$.

${ }^{5}$ Haferkamp O, Rosenau W, Lennert K. Vascular transformation of lymph node sinuses due to venous obstruction. Arch Path 1971;92:81-3.

- Castleman B, Iverson L, Menendez VP. Localized mediastinal lymph node hyperplasia resembling thymoma. Cancer $1956 ; 9: 822-30$.

${ }^{7}$ Diebold J, Bientz M, Daussy M, Dessirier JL, Tricot G, Reynes M, Rochemaure J. Hyperplasie lymphoïde angiofolliculaire de localisation médiastinale-Etude en immunofluorescence directe. Rev Fr Mal Respirat 1976;4:373-8.

${ }^{8}$ Keller AR, Hochholzer L, Castleman B. Hyaline vascular and plasma cell types of giant lymph node hyperplasia of the mediastinum and other locations. Cancer 1972; 29:670-83.

${ }^{9}$ Lubin J, Rywlin AM. Lymphoma-like lymph node changes in Kaposi's sarcoma. Arch Path 1971 ;92:338-41.

${ }^{10}$ Martenson J, Henrikson H. Immuno-hemolytic anemia in Kaposi's sarcoma with visceral involvement only. Acta Med Scand 1954;153:175-88.

${ }^{11}$ Ramos CV, Taylor HB, Hernandez BA, Tucker EF. Primary Kaposi's sarcoma of lymph node. Am J Clin Pathol 1976;66:998-1003. 
12 Anderson LG, Talal N. The spectrum of benign to malignant lymphoproliferation in Sjögren's syndrome. Clin Exp Immunol 1972;10:199-221.

${ }^{13}$ Diebold J, Zittoun R, Tulliez M, Reynes M, Tricot G, Bernadou A, Audouin J. Pseudo-lymphomes et syndromes lymphoprolifératifs malins au cours du syndrome de Gougerot-Sjögren. Sem Hôp Paris 1978;54:1033-1040.

14 Shearn MA. Sjögren's syndrome. In: Major Problems in Internal Medicine. Philadelphia: Saunders, 1971.

15 Frizzera G, Moran EM, Rappaport H. Angio-immunoblastic lymphadenopathy with dysproteinemia. Lancet 1974;2:1070-3.

16 Lukes RJ, Tindle BM. Immunoblastic lymphadenopathy. A hyperimmune entity resembling Hodgkin's disease. N Engl J Med 1975;292:1-18.

${ }^{17}$ Radaszkiewicz T, Lennert K. Lymphogranulomatosis X. Klinisches Bild, Therapie und Prognose. Dtsch Med Wochenschr 1975;100:1157-63.
${ }^{18}$ Diebold J, James JM, Dao C, Reynes M, Mignot L, Tricot G, Audouin J, Bilski-Pasquier G. Hyperplasie lymphoide immunoblastique pseudo-tumorale par hypersensibilité médicamenteuse. Arch Anat Cytol Path 1976;24:189-94.

19 Barthold DR, Kysela S, Steinberg AD. Decline in suppressor $T$ cell function with age in female NZB mice. $J$ Immunol 1974;112:9-16.

${ }^{20}$ Steinberg AD. Pathogenesis of auto-immunity in New Zealand mice. V. Loss of thymic suppressor function. Arthritis Rheum 1974;17:11-4.

Requests for reprints to: Professor J Diebold, Laboratoire d'Anatomie et de Cytologie Pathologiques, 21 Rue de l'Ecole de Médecine, Université Paris VI, 75270 Paris Cedex 06, France. 